\title{
Association between Foeto-maternal Bleeding and Hypertension in Pregnancy
}

\author{
PETER JONES,* M.D., D.C.H. ; ANGUS MCNAY, † B.SC., DIP.N.A.\&A.C., F.S.S. \\ WILLIAM WALKER, $\ddagger$ M.D., M.R.C.P., F.C.PATH.
}

$S^{\text {un }}$ mmary : A blind prospective survey of foetomaternal bleeding in 200 primiparous pregnancies was carried out in an investigation of a possible association between foeto-maternal bleeding and hypertension in pregnancy. Evidence of foeto-maternal bleeding was found in $61 \%$ of 36 hypertensive pregnancies, and in $51 \%$ of 160 normotensive pregnancies, a difference which is not statistically significant.

Significant differences between the hypertensive and the normotensive groups were found when foeto-maternal bleeding was related to gestation. In pregnancies that beeame hypertensive more foetal cells were found in the maternal circulation before week 36 than in normotensive pregnancies. In patients with oedema of the abdominal wall during pregnancy the incidence of foeto-maternal bleeding was significantly increased.

These findings seem to explain why pre-eclamptic toxaemia is a significant predisposing factor in women who later develop $R h$ antibodies. It is recommended that anti-D gammaglobulin should be offered to all $\mathrm{Rh}$ negative women with $R$ h-positive infants following a hypertensive pregnancy. Consideration should also be given to the question of administering anti-D gammaglobulin during $\mathbf{R h}$-negative hypertensive pregnancies if this procedure is proved to be both safe to mother and foetus and effective.

The results provide contributory evidence that the placental vascular changes in toxaemic pregnancies precede the clinical signs and are not the result of hypertension.

\section{Introduction}

In Great Britain only about 1 in 15 of those pregnancies that involve an $\mathrm{Rh}$-negative mother and an $\mathrm{Rh}$-positive foetus result In $\mathrm{Rh}$ isoimmunization.

There is no genetic explanation for this (Booth et al., 1953 ; Knox and Walker, 1957), and as Rh substance occurs only in erythrocytes (Walker and Bailey, 1956 ; Levine and Celano, 1961 ; Lawler and Shatwell, 1962) it is postulated that foetal erythrocytes enter the maternal circulation during pregnancy to Initiate the process. In favour of this hypothesis has been the observation that ABO incompatibility between mother and foetus protects against immunization (Levine, 1943; Knox et al., 1960), though this has been challenged by Ascari et al. (1969). In any event this could explain only why 3 of 14 cases do not become immunized. The remaining 11 pregnancies must be protected either by an unknown factor or by the absence of significant foeto-maternal bleeding.

Using the Kleihauer tochnique many workers have shown foetal cells in the maternal circulation, often near the time of delivery (Woodrow and Finn, 1966), but sometimes much earlier in pregnancy (Zipursky et al., 1963), and it is generally

\footnotetext{
- Registrar in Medicine, Royal Victoria Infirmary, Newcastle upon Tyne. † Statistician to the Newcastle Regional Hospital Board.

¥ Reader in Paediatric Haematology, Department of Child Health, Royal Victoria Infirmary, Newcastle upon Tyne.
}

accepted that foeto-maternal bleeding does provide the stimulus for $\mathrm{Rh}$ isoimmunization.

Present programmes for preventing $\mathrm{Rh}$ isoimmunization are mainly based on the administration of anti-D gammaglobulin to $\mathrm{Rh}$-negative primiparae. If applied to all such patients 100 women would receive treatment in order to prevent 10 cases of isoimmunization or one perinatal death. The identification of a high-risk group of women might result in a more economically and medically justifiable programme, and indeed this is at present attempted by routine Kleihauer counts after delivery. This is of limited value because of technical difficulties and because isoimmunization occurs in a number of patients who do not have foetal cells demonstrated at this time.

Knox et al. (1961) reported an association between $\mathrm{Rh}$ isoimmunization and the occurrence of toxaemia, traumatic delivery, and abnormalities of the placenta. Knox (1968) found that pre-eclamptic toxaemia appeared to be a predisposing factor in $50 \%$ of the women who later developed $\mathrm{Rh}$ antibodies. If this association is real, and if foetal bleeding is the stimulus, there should be a relation between toxaemia and foeto-maternal bleeding.

The present communication describes a prospective study designed to explore this hypothesis.

\section{Material}

Two hundred consecutive primiparae were selected from women booking delivery at the Princess Mary Maternity Hospital. The only patients rejected were those with an uncertain menstrual history, making estimation of the expected date of delivery difficult, and those who were unlikely to attend the clinic regularly.

Primiparae were chosen because of the high incidence of toxaemia-16.9\% compared with $9.3 \%$ in multiparae (Newcastle upon Tyne Maternity Survey, 1960-64). All the patients were admitted to the survey before the 30th week of pregnancy.

Of the original 200 women six had early abortions, five left the district, two subsequently admitted previous pregnancies, two were not pregnant, one failed to attend, and one was excluded because she became psychologically disturbed. Seventeen new patients were selected to take their places.

Two of the 200 primiparae delivered stillbirths and two produced twins. The major statistical analysis was confined to the remaining 196 pregnancies that resulted in single live-births.

\section{Method}

Previous to the selection of patients a scheme for the accurate recording of the historical facts and clinical details likely to be of interest at each stage of pregnancy, labour, and delivery was drawn up. After each hospital visit and inpatient stay relevant details were to be entered on a form designed for later data processing by computer. When more detailed information than was normally available in the routine hospital records was required, questionaries were included in the notes and completed by the doctor examining the patient. 
Blood samples were required from each patient at monthly intervals before the 30th week of pregnancy, and thereafter at weekly intervals. These were usually skin-prick samples taken into heparin and kept at $4^{\circ} \mathrm{C}$. until films could be made within 48 hours of collection for elution by the Kleihauer technique. At 30-32 weeks' gestation, 36 weeks' gestation, and postnatally venous specimens were taken into edetic acid for elution and into dry tubes for blood grouping and antibody tests. Cord blood specimens were obtained at delivery for ABO and rhesus grouping and for elution.

\section{Elution}

Films were prepared from measured 2-microlitre volumes of blood by means of a semi-automatic film maker (Jones, 1969), and were eluted in a citric acid phosphate buffer at $\mathrm{pH}$ 3.4-3.6 at $37^{\circ} \mathrm{C}$. for five minutes (Kleihauer et al., 1957). They were stained with haematoxylin and eosin. The technique results in the elution of adult haemoglobin ( $\mathrm{Hb} \mathrm{A}$ ) from the maternal erythrocytes, which appear as ghosts on microscopy. Foetal cells retain their haemoglobin ( $\mathrm{Hb} \mathrm{F}$ ) and stain red with eosin.

In order to eliminate observer bias all slides were identified only with record numbers. They were mixed so that no slides could be related to a particular group of women, or to a particular day of collection, without reference to the code. This code was not broken until all the slides had been screened and foetal cells counted. As an additional check a series of films made from artificial mixtures, and similarly numbered, were interleaved with the survey slides.

Each film was examined independently by two observers, and at intervals their results were compared. Initial screening was carried out under low-power magnification $(\times 80)$; a thin layer of oil was spread over the film to increase the refraction of foetal cells and facilitate identification. All cells suspected of being foetal in origin were examined under the high-power oil-immersion lens (magnification $\times 1,000$ ).

Films were designated " positive," " ? positive," or " negative." Slides were classified as negative only after the entire film had been studied, but positive or ? positive if any probable foetal cells were seen.

\section{Quantification}

All positive or ? positive slides were re-examined completely. Doubtful foetal cells were examined under the high-power oilimmersion" lens. "Intermediate cells" (cells taking up eosin stain in a patchy distribution and often found in normal nonpregnant adults) and cells of uncertain origin after high-power examination were not counted. All foetal cells in the film were counted. Because it was thought that the distribution of foetal cells in a film was not random (Jones, 1969), films with large uneluted areas were discarded.

A graph, prepared from the results obtained with artificial mixtures of foetal in maternal blood (Table I), was used to convert the total number of foetal cells per film into their dilution in maternal blood (Jones, 1969).

TABLE I.-Foetal Cell Counts from 2-microlitre Samples of Artificial Mixtures of Foetal Blood, from a Baby of 32 Weeks' Gestation, in Adult Blood. Ten Films were Examined at Each Dilution

\begin{tabular}{c|c|c}
\hline \multirow{2}{*}{$\begin{array}{c}\text { Dilution } \\
\text { Foetal Cell : Adult Cclls }\end{array}$} & \multicolumn{2}{|c}{ No. of Foetal Cells } \\
\cline { 2 - 3 } & Range & Mean Count \\
\hline $1: 100,000$ & $3-9$ & $4 \cdot 5$ \\
$1: 80,000$ & $6-10$ & $8 \cdot 2$ \\
$1: 50,000$ & $11-23$ & $16 \cdot 8$ \\
$1: 40,000$ & $17-31$ & $23 \cdot 2$ \\
$1: 30,000$ & $27-40$ & $33 \cdot 4$ \\
$1: 20,000$ & $39-58$ & $46 \cdot 3$ \\
$1: 10,000$ & $46-81$ & $67 \cdot 0$ \\
$1: 5,000$ & $209-308$ & $262 \cdot 2$ \\
$1: 2,500$ & $897-1,519$ & $1,126 \cdot 2$ \\
$1: 500$ & $2,148-4,668$ & $3,716 \cdot 2$ \\
\hline
\end{tabular}

In the subsequent analyses the incidences of foeto-maternal bleeding were calculated with and without the inclusion of counts of only one foetal cell per film because of the very occasional finding of an uneluted "foetal type" cell in the blood of healthy non-pregnant adults.

\section{Definition of "Hypertension in Pregnancy"}

The term " toxaemia of pregnancy" probably includes several disease entities, and neither the textbook triad of hypertension, oedema, and albuminuria nor the clinical impression of an individual doctor is a reliable criterion for research purposes. In particular oedema is so common during pregnancy as to be considered a physiological rather than a pathological finding (Hytten and Leitch, 1964). In order to isolate a discrete group of patients with abnormal blood pressure from the patients studied, the criteria of Nelson (1955) were adopted.

Any woman with a diastolic pressure of $90 \mathrm{~mm}$. $\mathrm{Hg}$ or above on two occasions (the readings being made at an interval of at least 24 hours) after the 26 th week of pregnancy was designated " hypertensive."

Thirty-six women were " hypertensive" during pregnancy, an incidence of $18 \%$. In addition to complying with the basic criteria 29 of the 36 were diagnosed on clinical grounds as having either "pre-eclamptic toxaemia" or " hypertension of pregnancy." One patient's hypertension was secondary to polycystic kidney disease.

\section{Results}

The mean number of films examined per hypertensive patient was 7.66 ; per normotensive patient it was $7 \cdot 25$. The mean duration of pregnancy in the two groups was the same (39 weeks). The women in the hypertensive group showed a mean weight gain of $363 \mathrm{~g}$. per week during pregnancy, compared with a mean weight gain of $249 \mathrm{~g}$. per week for the normotensive women. The mean birth weight for the babies of hypertensive mothers was 3,246 g., and for the babies of normotensive mothers $3,252 \mathrm{~g}$. The frequency of foeto-maternal bleeding in hypertensive and non-hypertensive patients is shown in Table II.

TABLE II.-Incidence of Foeto-maternal Bleeding ( $>1$ Foetal Cell per Film) in 36 Hypertensive and 160 Normotensive Pregnancies

\begin{tabular}{|c|c|c|c|}
\hline & $\begin{array}{l}\text { Hypertensive } \\
\text { Pregnancies }\end{array}$ & $\begin{array}{c}\text { Normotensive } \\
\text { Pregnancies }\end{array}$ & Total \\
\hline $\begin{array}{l}\text { Patients with demonstrable } \\
\text { foeto-maternal bleeding } \\
\text { Patients without demonstrable } \\
\text { foeto-maternal bleeding }\end{array}$ & $\begin{array}{l}22 \\
14\end{array}$ & $\begin{array}{l}82 \\
78\end{array}$ & $\begin{array}{r}104 \\
92\end{array}$ \\
\hline Total $\quad \ldots$ & 36 & 160 & 196 \\
\hline
\end{tabular}

Although foeto-maternal bleeding (of more than one foetal cell per film) was found in $61 \%$ of the hypertensive women and in $51 \%$ of the normotensive women at some stage in their pregnancies, there was no statistically significant difference in incidence between the groups.

\section{Determination of Size of Foetal Bleeds}

At any one time the number of foetal cells present in the maternal blood may represent a single bleed from the foetus or may be the product of an accumulation of cells from a series of earlier bleeds. The mean life-span of the foetal cell is about 80 days (Pearson, 1967), so that positive foetal cell counts at any stage of pregnancy or delivery may bear no relation to the timing of a bleed within at least this limit. Presumptive evidence of fresh bleeding can be obtained only if, during a series of examinations, the number of foetal cells present in 
TABLE III.-Mean Foetal Cell Counts for Gestation in Normotensive and Hypertensive Pregnancies

\begin{tabular}{|c|c|c|c|c|c|c|c|c|c|c|c|c|c|}
\hline & Gestation (Week & & 32 & 33 & 34 & 35 & 36 & 37 & 38 & 39 & 40 & \multicolumn{2}{|c|}{$41+42$} \\
\hline \multirow{2}{*}{$\begin{array}{l}\text { Normotensive } \\
\text { pregnancies }\end{array}$} & $\begin{array}{l}\text { No. of foetal cells } \\
\text { No. of counts }\end{array}$ & .. & $\begin{array}{r}131 \\
67\end{array}$ & $\begin{array}{r}265 \\
69\end{array}$ & $\begin{array}{r}122 \\
84\end{array}$ & $\begin{array}{r}194 \\
83\end{array}$ & $\begin{array}{l}525 \\
127\end{array}$ & $\begin{array}{l}2,762 \\
128\end{array}$ & $\begin{array}{l}9,486 \\
111\end{array}$ & $\begin{array}{l}4,567 \\
104\end{array}$ & $\begin{array}{l}3,600 \\
72\end{array}$ & 1,925 & $\begin{array}{l}6 \\
4\end{array}$ \\
\hline & Mean cell count & . & 1.96 & $3 \cdot 84$ & 1.45 & $2 \cdot 34$ & $4 \cdot 13$ & $21 \cdot 58$ & $85 \cdot 46$ & 43.91 & $50 \cdot 00$ & $62 \cdot 3$ & \\
\hline \multirow{2}{*}{$\begin{array}{l}\text { Hypertensive } \\
\text { pregnancies }\end{array}$} & (Mean cell count & . & $7 \cdot 50$ & $52 \cdot 70$ & 6.50 & $241 \cdot 07$ & 29.93 & $8 \cdot 00$ & $70 \cdot 67$ & $8 \cdot 75$ & $5 \cdot 08$ & $10 \cdot 8$ & \\
\hline & $\begin{array}{l}\text { No. of foetal cells } \\
\text { No. of counts }\end{array}$ & .. & $\begin{array}{r}165 \\
22\end{array}$ & $\begin{array}{l}1,527 \\
10\end{array}$ & $\begin{array}{r}130 \\
20\end{array}$ & $\begin{array}{c}3,375 \\
14\end{array}$ & $\begin{array}{r}898 \\
30\end{array}$ & $\begin{array}{r}240 \\
30\end{array}$ & $\begin{array}{l}1,484 \\
21\end{array}$ & $\begin{array}{r}140 \\
16\end{array}$ & $\begin{array}{l}66 \\
13\end{array}$ & $\begin{array}{r}49 \\
3\end{array}$ & $\begin{array}{l}5 \\
2\end{array}$ \\
\hline Runs test seque & ence* & .. & - & - & - & - & - & + & + & + & + & & \\
\hline
\end{tabular}

* indicates a higher score for the hypertensive group and + indicates a higher score for the normotensive group.

a standard volume of maternal blood increases significantly. There are thus two ways of approaching the problem of size. The first is to express results as mean cell counts for gestation; the second is to determine the occurrence and size of individual fresh bleeds within a series.

\section{(a) Mean Cell Counts for Gestation}

When the total number of foetal cells counted in all the specimens obtained during a given week of pregnancy are divided by the total number of specimens the result is the mean foetal cell count for the particular group of women studied. Mean foetal cell counts were performed for each week of pregnancy for the hypertensive and the normotensive women. The results are shown in Table III.

Before week 32 there was no statistically significant difference between the groups. Thereafter the mean foetal cell counts for the hypertensive group were persistently higher than those for the normotensive group until week 37 . The pattern was then completely reversed, the mean cell counts for the normotensive group becoming higher until term. Application of the onesample Runs test to the sequence shown below the counts in Table III produced a significant result, indicating that this sequence is non-random, and suggesting significantly higher mean cell counts for the hypertensive group up to week 37 of pregnancy and for the normotensive group thereafter.

Because of the gross skewness of the distributions involved, however, it is not strictly correct to compare mean cell counts. For example, the very large mean cell count for the hypertensive group at 35 weeks was due to a count of 3,219 foetal cells in the film of one patient, and this single count grossly distorts the mean. This and similar large differences from normality preclude parametric comparison, and the hypertensive and normotensive count distributions for each week were therefore compared by means of the non-parametric MannWhitney test. The results of this comparison are shown in Table IV.

TABLE IV.-Comparison of Ranked Foetal Cell Counts (Mann-Whitney Test). Foetal Cell Counts for Hypertensive Patients Have Been Compared with Those for Normotensive Patients from Week 32 of Pregnancy to Term. Only the Results at 32 and 33 Weeks are
Significant Significant

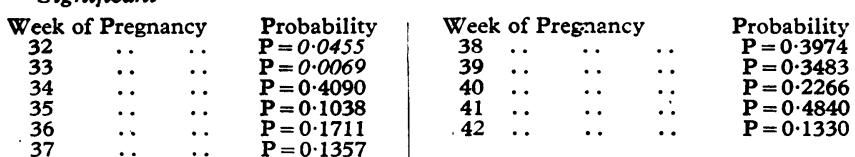

Foetal cell counts for the hypertensive patients were found to be higher than those for normotensive patients in weeks 32 and 33 of gestation $(P=0.045$ at 32 weeks; $P=0.007$ at 33 weeks). There was no statistically significant difference between the groups at any other stage of pregnancy.

These results suggest that as pregnancy advances more foetal cells enter the maternal circulation, but that this rise in cell counts occurs earlier in hypertensive than in normotensive patients. The earlier rise in the hypertensive group cannot be explained by the contribution of a few pregnancies of short duration with high foetal cell values before week 36 -that is, if it is assumed that approaching labour in any woman may increase the likelihood of a foeto-maternal bleed. The mean duration of pregnancy for the five hypertensive patients with foetal cell counts of over 100 cells in a film was the same as that for those hypertensive women with lower foetal cell scores (39.6 weeks).

\section{(b) Fresh Foetal Bleeding During Pregnancy}

In order to determine the occurrence of a fresh bleed all the foetal cell counts were considered in terms of their dilution in maternal blood. The standard dilutions shown in Table I had been determined by the values of the artificial dilutions. Because of the overlap in the ranges of foetal cell counts for the higher dilutions a fresh foetal bleed was diagnosed only when the decrease in dilution was greater than the next standard dilution in the series. In the 196 pregnancies 158 fresh bleeds were diagnosed and plotted according to size and gestation (see Chart).

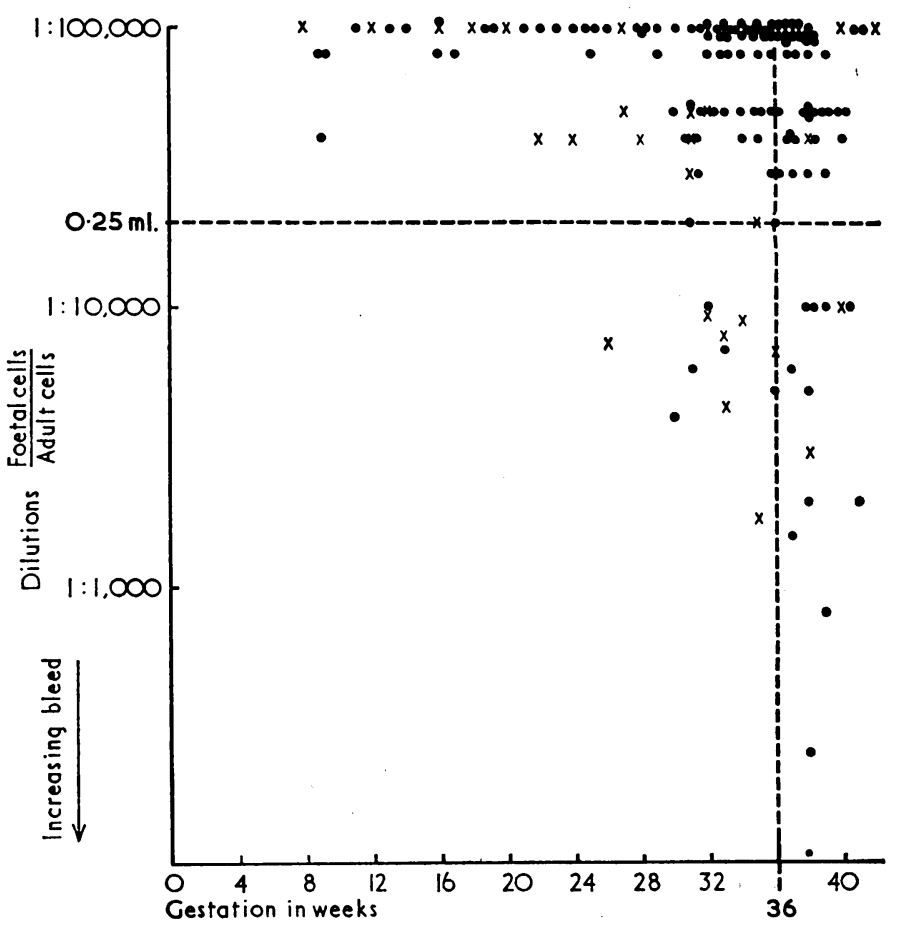

The 158 fresh foeto-maternal bleeds occurring in 196 pregnancies. Larger-volume foetal bleeds in 36 hypertensive $(x)$ pregnancies appear to occur at earlier gestations than those of equivalent volume in 160 normotensive $(\boldsymbol{O})$ pregnancies.

In the Chart a division has been drawn at a dilution of one foetal cell :20,000 adult cells. In a woman with a blood volume of 5 litres this dilution represents a foetal bleed of $0.25 \mathrm{ml}$., and it is this volume that has been arbitrarily taken as that required to stimulate antibody formation in $\mathrm{Rh}$-negative women (Woodrow et al., 1965). Another, vertical, line divides the bleeds at a gestation of 36 weeks. 
From the Chart it is apparent that a cluster of fresh bleeds of a volume of $0.25 \mathrm{ml}$. or over occurred in the hypertensive pregnancies before week 36 .

Fresh bleeding was diagnosed more than once in the pregnancies of several patients. Eight fresh bleeds of $0.25 \mathrm{ml}$. or over occurred in six of the hypertensive group at or before week 36. Each of the comparable bleeds in the normotensive group was from an individual patient. In Table $\mathrm{V}$ the numbers of hypertensive and normotensive patients with fresh bleeding of $0.25 \mathrm{ml}$. or over are considered according to gestation.

TABLE V.- $\chi^{2}$ Comparison of 160 Normotensive and 36 Hypertensive Patients With and Without Fresh Foetal Bleeds of $0.25 \mathrm{ml}$. or Over According to Gestation. The Results for $A$ and $C$ are Significant \begin{tabular}{c|c|c} 
According to Gestation. The Results for $A$ and $C$ are Significant \\
$\qquad \begin{array}{c}\text { Fresh Bleed } \\
0.25 \mathrm{ml} . \\
\vdots 02.25 \mathrm{ml} .\end{array}$ & $\begin{array}{c}\text { No Fresh Bleeding } \\
>0.25 \mathrm{ml} .\end{array}$ & Total
\end{tabular}

\begin{tabular}{|c|c|c|c|c|c|}
\hline \multirow{2}{*}{\multicolumn{2}{|c|}{$\begin{array}{l}\text { Normotensive patients } \\
\text { Hypertensive patients .. }\end{array}$}} & \multirow{2}{*}{\multicolumn{2}{|c|}{ (A) $\begin{array}{c}0-35 \text { Weeks } \\
7 \\
6\end{array}$}} & \\
\hline & & & & $\begin{array}{r}153 \\
30\end{array}$ & $\begin{array}{r}160 \\
36\end{array}$ \\
\hline Total .. & .. & 13 & & 183 & 196 \\
\hline
\end{tabular}

(B) 36 Weeks to Term

\begin{tabular}{|c|c|c|c|c|}
\hline $\begin{array}{l}\text { Normotensive patients } \\
\text { Hypertensive patients }\end{array}$ & & $\begin{array}{l}8 \\
2\end{array}$ & $\begin{array}{r}152 \\
34\end{array}$ & $\begin{array}{r}160 \\
36\end{array}$ \\
\hline Total .. & .. & 10 & 186 & 196 \\
\hline
\end{tabular}

(C) Overall Pregnancy

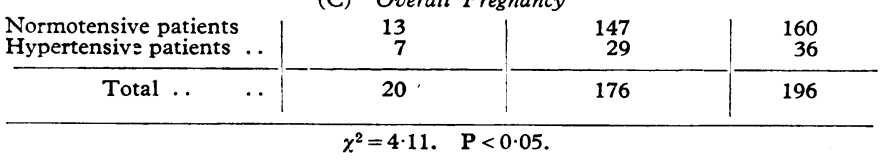

Before week 36 of pregnancy significantly more fresh bleeds of $0.25 \mathrm{ml}$. or over occurred in the hypertensive group than in the normotensive group $(P<0 \cdot 01)$. From week 36 to term there was no significant difference between the groups. Taking pregnancy as a whole, significantly more hypertensive women had bleeds of $0.25 \mathrm{ml}$. or over than the normotensive women $(\mathrm{P}<0.05)$.

From this survey it is apparent that the chances of finding a fresh bleed of a volume likely to result in $\mathrm{Rh}$ isoimmunization at any stage of pregnancy are small, only about one count in 60 representing a foetal bleed of over $0.25 \mathrm{ml}$. The chances of a foetal bleed of this volume before week 36 being from a hypertensive patient, however, are very high ( 1 in 20 , compared with 1 in 110 for the normotensive patient).

\section{Oedema and Albuminuria}

Of the 196 women, $71 \%$ were found to have oedema of one or more sites at some stage of pregnancy. The incidence according to site was: ankles $64 \%$, fingers $53 \%$, abdominal wall $18 \%$, face $9 \%$, sacrum $4 \%$, vulva $0.5 \%$. Oedema was present in 26 of the 36 hypertensive patients during pregnancy.

The presence or absence of foeto-maternal bleeding (of more than one foetal cell per film) was determined for women with or without oedema. Although there was no significant difference between the groups for overall incidence, a significantly higher proportion of women with oedema of the abdominal wall had been recipients of foetal blood during their pregnancies (Table VI).

Albumin was found in the urine of $16(8 \%)$ of the 196 primiparae. In only five patients was a concentration of more than a "trace" recorded on testing with Albustix. Four of these patients, with albuminuria of $2 \mathrm{~g}$./litre, were also hypertensive. In one of them, and in the normotensive patient with $2 \mathrm{~g}$. of albuminuria per litre, the concentrations were measured in ordinary urine specimens. No relation was found between albuminuria and foeto-maternal bleeding.

\begin{tabular}{|c|c|c|c|}
\hline & $\begin{array}{l}\text { Abdominal Wall } \\
\text { Oedema Absent }\end{array}$ & $\begin{array}{l}\text { Abdominal Wall } \\
\text { Oedema Present }\end{array}$ & Total \\
\hline $\begin{array}{l}\text { Patients with demonstrable } \\
\text { foeto-maternal bleeding } \\
\text { Patients without demonstrable } \\
\text { foeto-maternal bleeding } \quad . .\end{array}$ & $\begin{array}{l}79 \\
81\end{array}$ & 10 & 105 \\
\hline Total $\quad \ldots$ & 160 & 36 & 196 \\
\hline
\end{tabular}

\section{Clinical Signs in Hypertensive Pregnancies}

The gestations at which the first appearances of hypertension, oedema, or albuminuria occurred in the 36 hypertensive pregnancies were determined. The mean gestation for the appearance of hypertension in 35 patients (the patient with polycystic kidneys being excluded) was 36.3 weeks. Oedema was first recorded at a mean gestation of 34 weeks and albuminuria at 36 weeks.

In those pregnancies with demonstrable foeto-maternal bleeding hypertension was preceded by more fresh foetomaternal bleeds of a greater volume than were demonstrated in normotensive pregnancies at an equivalent period of gestation.

\section{Analysis of Other Factors During Pregnancy}

No significant differences between the hypertensive and the normotensive groups were found in analyses of maternal and foetal $\mathrm{ABO}$ and rhesus groups, maternal age, marital status, previous disease, or illness, operation, and accidents during pregnancy.

\section{Discussion}

The possibility of an association between foeto-maternal bleeding and toxaemia of pregnancy was first postulated by Dienst (1905), who thought that incompatible foetal bleeds caused eclampsia. Ottenberg (1923) extended this hypothesis, and suggested that jaundice of the newborn had a similar aetiology. Javert and Reiss (1952) found dissimilarity between maternal and foetal $\mathrm{ABO}$ and rhesus groups to be no more prevalent in toxaemic than in normal pregnancies, and this was the finding in the present study.

Little direct evidence of an association between foetal bleeding and toxaemia has been reported, possibly because attention has been given more to the sequelae of toxaemic complications in late pregnancy and delivery. A foetal bleed into the maternal circulation was demonstrated by Bromberg et al. (1956) in a case of pre-eclampsia and intrauterine death, and Sansone et al. (1960) found foetal blood in a woman with albuminuria during pregnancy. McLarey and Fish (1966) reported evidence of foetal bleeding before intrauterine death and eclampsia in one patient, and proved it in another woman with hypertension secondary to chronic pyelonephritis. Pilkington et al. (1966) found that the mean foetal cell counts in pre-eclamptic patients were higher than those in normal women in late pregnancy, but their results did not achieve statistical significance.

In the present communication we have shown that foetal blood of more than the usual volume may enter the maternal circulation before week 36 of pregnancy in mothers who subsequently develop hypertension. The study of the mean foetal cell counts between week 32 of pregnancy and term indicated that more foetal cells were present in hypertensive patients before week 36 , and that more foetal cells were present in normotensive patients after this. Although this change might 
be explained by the removal of ageing foetal cells from earlier bleeds in the hypertensive group as cells from later bleeds in the normotensive group accumulated, further analysis showed that the differences between the groups, in terms of the number of foetal cells circulating, were significant only at 32 and 33 weeks. In particular, the abrupt change between 36 and 37 weeks had no statistical significance wher the errors inherent in comparing grossly skewed distributions were acknowledged.

The demonstration of an increase in the volume of foetal bleeds as pregnancy advanced (see Chart) is in agreement with the results of Woodrow and Finn (1966), who found a progressive rise in foetal blood volumes within the maternal circulation during the third trimester. In uncomplicated pregnancies this increase is presumably due to more, or larger, breaks occurring in the ageing placental barrier. In hypertensive pregnancies the increase occurs earlier, and is not equalled by that in normotensive pregnancies until the 37 th week.

We have intentionally studied hypertension, oedema, and albuminuria separately because of the difficulty in applying a strict definition to the term " toxaemia of pregnancy." Thirtytwo of the hypertensive group studied had their blood pressures measured in hospital, and the analysis of results was rechecked with the exclusion of the four women who were admitted only for delivery. One of these was a proved case of polycystic renal disease. The conclusions reached with regard to the incidence and size of foeto-maternal bleeds remain valid after the exclusion of these patients. The finding of a higher mean rate of increase in weight for the hypertensive women is in accord with the known association between an increasing incidence of pre-eclampsia with increasing weight gain, the incidence accelerating at high weights (Hytten and Leitch, 1964). Because of the specific association of hypertension and foetal bleeding, the results probably apply to any group of women with toxaemia provided the definition of their disease includes reference to a higher than normal diastolic pressure.

Although it is thought that a single large foeto-maternal bleed at delivery may lead to $\mathrm{Rh}$ isoimmunization, it is possible that more than one foetal bleed is necessary to stimulate antibody production in a $\mathrm{Rh}$-negative woman. The combination of significant foetal bleeding before week 36 of gestation, and the higher incidence of complications of late pregnancy and delivery which are likely to result in further foetal bleeds, may explain why toxaemia is a significant precipitating factor in women who later develop $\mathrm{Rh}$ antibodies. The present evidence suggests that toxaemic patients form a significant proportion of a high-risk group of Rh-negative women, who should be offered anti-D gammaglobulin irrespective of Kleihauer counts at delivery. The possible value of administering anti-D gammaglobulin during $\mathrm{Rh}$-negative hypertensive pregnancies must depend on proof of such a procedure being both safe to mother and foetus and effective in preventing immunization.

The significance of the findings in relation to the disease processes that result in the clinical syndrome of toxaemia of pregnancy is difficult to define. That the placental vasculature undergoes changes in toxaemic pregnancies is well known. In this study we have shown that foetal cells may cross the placenta in larger numbers than normal before the appearance of clinical signs. This suggests that the vascular damage in toxaemia is a manifestation of an earlier disease process, that cells escape from the foetal circulation as a result of the damage, and that the clinical manifestations of the disease are a late indication of a process which has started before the third trimester. Although the nature of the vascular damage is unknown, the higher incidence of toxaemia in primigravidae suggests that a group-specific process is involved, and that the incidence falls in multiparae as these women complete their families and leave the at-risk group. Whether women who have suffered from toxaemia are more liable to other diseases in later life because of the placental vascular breaks presumably associated with their disorder of pregnancy is at present unknown.
The association between oedema of the abdominal wall and a higher than expected incidence of foeto-maternal bleeding may help to explain the clinical features of the maternal syndrome, in which a hydropic foetus may be associated with the appearance of toxaemia and particularly with abdominal wall oedema in the mother.

As transfusion reactions may be caused by foeto-maternal bleeding (Chown, 1954; Samet and Bowman, 1961; Fairweather and Walker, 1964), and as the pathological findings in cases of eclampsia include those of intravascular coagulation (McKay, 1965), it might be worth while to examine the blood of eclamptics for foetal cells. The suggestion is attractive because it presents an immediate therapeutic approach to severe toxaemia and eclampsia with anticoagulant or fibrinolytic agents.

We wish to thank the medical and nursing staff of the Princess Mary Maternity Hospital, Newcastle upon Tyne, for access to patients under their care, and for invaluable help in the collection of specimens and data; and the staff of the Statistical and Computing Laboratory of the Newcastle Regional Hospital Board for assistance given. We are grateful to the staff of the Attic Laboratory, Royal Victoria Infirmary, particularly to Mrs. Ann Randall, who prepared the blood films, and to the staff of the Newcastle Regional Transfusion Centre who performed the blood grouping. Assistance was also received from Professor D. V. I. Fairweather and Professor E. G. Knox, and from the staff of the M.R.C. Growth and Reproduction Unit, Newcastle, to whom we are grateful.

The work reported formed part of a thesis for the degree of Doctor of Medicine in the University of Newcastle upon Tyne (P. J.). We are grateful for financial assistance from the Medical Research Council and the Research and Scientific Committee of the Royal Victoria Infirmary.

\section{REFERENCES}

Ascari, W. Q., Levine, P., and Pollack, W. (1969). British Medical fournal, 1, 399.

Booth, P. B., Dunsford, I., Grant, J., and Murray, S. (1953). British Medical fournal, 2, 41.
M., Salzberger, M., and Abrahamov, A. (1956). Obstetrics and Gynaecology, 7, 672.

Chown, B. (1954). Lancet, 1, 1213.

Dienst, A. (1905). Zentralblatt für Gynãkologie, 29, 353.

Fairweather, D. V. I., and Walker, W. (1964). Fournal of Obstetrics and Gynaecology of the British Commonwealth, 71, 48.

Hytten, F. E., and Leitch, I. (1964). The Physiology of Human Pregnancy. Oxford, Blackwell.

Javert, C. T., and Reiss, C. (1952). Surgery, Gynaecology, and Obstetrics, 94, 257 ,

Jones, P. (1969). British Medical fournal, 2, 85.

Kleihauer, E., Braun, H., and Betke, K. (1957). Klinische Wochenschrift, 35, 637.

Knox, E. G. (1968). Lancet, 1, 433.

Knox, E. G., Murray, S., and Walker, W. (1960). British fournal of

Preventive and Social Medicine, 14, 77.
Knox, E. G., Murray, S., and Walker, W. (1961). fournal of Obstetrics and Gynaecology of the British Commonwealth, 68, 11 .

and Gynaecology of the British Commonwealth, 68, Pritish fournal of Preventive and Social Medicine, 11, 126.

Lawler, S. D., and Shatwell, H. S. (1962). Vox Sanguinis, 7, 488.

Levine, P. (1943). Fournal of Paediatrics, 23, 656.

Levine, P., and Celano, M. J. (1961). Vox Sanguinis, 6, 720.

McKay, D. G. (1965). Disseminated Intravascular Coagulation. London, Harper and Row.

McLarey, D. C., and Fish, S. A. (1966). American fournal of Obstetrics and Gynecology, 95, 824 .

Nelson, T. R. (1955). Fournal of Obstetrics and Gynaecology of the British Commonwealth, 62, 48.

Ottenberg, R. (1923). Journal of the American Medical Association, 81, 295.

Pearson, H. A. (1967). Fournal of Paediatrics, 70, 166.

Pilkington, R., Knox, E. G., Russell, J. K., and Walker, W. (1966). fournal of Obstetrics and Gynaecology of the British Commonwealth, 73, 909 .

Samet, S., and Bowman, H. S. (1961). American fournal of Obstetrics and Gynaecology, 81, 49.

Sansone, G., Borrone, C., and Massimo, L. (1960). Minerva Paediatrica, 12, 1215.

Walker, W., and Bailey, B. M. (1956). Fournal of Clinical Pathology, 9, 52 .

Woodrow, J. C., et al. (1965). British Medical fournal, 1, 279.

Woodrow, J. C., and Finn, R. (1966). British fournal of Haematology,

12, 297.
Zipursky, A., Pollock, J., Neeiands, P., Chown, B., and Israels, L. C. (1963). 'Lancet, 2, 489 